\title{
The Effect of Unilateral and Bilateral Foot Dominance on Sprinting Speed of Young Athletes*
}

\author{
Muzaffer Selçuk ${ }^{1}$, Mehmet Akif Ziyagil ${ }^{2}$, Orhan Şener ${ }^{3}$ \\ ${ }^{1}$ Yüzüncü Yıl University, School of Physical Education and Sports, Van, Turkey \\ ${ }^{2}$ Mersin University, School of Physical Education and Sports, Mersin, Turkey \\ ${ }^{3}$ Selçuk University, Faculty of Sports Sciences, Konya, Turkey \\ Correspondence: Mehmet Akif Ziyagil, School of Physical Education and Sports, Mersin, Turkey.
}

Received: February 25, 2019

Accepted: March 17, 2019

Online Published: March 19, 2019

doi:10.11114/jets.v7i4.4150

URL: https://doi.org/10.11114/jets.v7i4.4150

\begin{abstract}
Purpose: Footedness as a predictor of brain hemispheric dominance cause performance differences in movement and sports performance. This study aimed to investigate the $30 \mathrm{~m}$ sprint speed difference between unilateral and bilateral foot dominance in 156 male and 37 female athletes.
\end{abstract}

Material Method: It was assumed that all participants exerted maximum effort during $30 \mathrm{~m}$ sprint test in the entrance examination for schools of physical education and sports. The participants with right and left foot dominance were accepted as "unilateral footed" while participants kicking the ball with two foot were recognized as "bilateral footed". For testing differences between two groups Mann Whitney $\mathrm{U}$ tests were used.

Results: There was only significant difference in the second attempt of 30 meters sprints between unilateral and bilateral footed male participants. Bilateral footed males were $2.81 \%$ faster than unilateral footers. Sprint speed difference was $11.97 \%$ for first trial and $10.43 \%$ for second trial in between unilateral and bilateral footed female participants. However, this difference was statistically insignificant due to lower number of bilateral athletes in our study.

Conclusion: Unilateral and bilateral foot dominance can be useful criteria in the selection of talented sprinters and in the planning and monitoring of training.

Keywords: unilateral, bilateral, footedness, sprint

\section{Introduction}

Sprinting performance can be evaluated as a function of the propulsive forces generated by the left and right sides of the body. Although similar contributions to propulsion might be anticipated from both body sides, a number of studies have shown differences in technique coordination and propulsive forces between left and right sides. Large strength imbalances on foot dominance were observed in both sedentary and exercise-trained individuals (Ziyagil, Gursoy, Dane \& Yuksel, 2010; McGrath, Waddington, Scarvell, Ball, Creer, Woods \& Smith, 2016; Brown, Feldman, Cross, Helms, Marrier, Samozino, \& Morin, 2017). These asymmetries may be a risk for injury and decrease physical or sporting performance level (McGrath et al., 2016; Brown et al., 2017).

Researchers showed that hand preference is under more cultural pressure than foot preference; thus, foot dominance is more neutral and useful than hand dominance in exploring specific dimensions of neuropsychological function in children (Searleman, 1980; Chapman, Chapman, \& Allen, 1987; Peters, 1990; Gabbard, 1993).

Although sprinting occurs in a linear direction, displacement of the body during running is due to the resultant forces produced by the back and forth movements of right and left arms plus the pushing force of the right and left legs. To investigate the handedness and footedness relations to differences in sprinting speed (Ziyagil, 2011). Ziyagil (2011) stated that right-handed participants had significantly higher mean running speeds than left-handers, whereas no significant difference was observed between the mean values of right- and left-footed participants. Sprint speed was

*This study was presented in the 10th International Conference in Physical Education, Sports and Physical TherapyICPESPT-2016. Elazig, Turkey. 
depending on the number of sprints and handedness, but not footedness. Obviously, the right-handed prepubertal wrestlers had a significant advantage for short sprint speed in comparison to the left-handers. It may be considered that left brain hemisphere dominance in right-handers is related to sprinting ability and may contribute to better acceleration during multiple sprints, creating fast movements advantageous for right-handers (Ziyagil, 2011). On the other hand, Singh (1970) studied the leg strength in a pushing activity and found that the right-leg strength of right-handed subjects was not different than their left legs, but showed that left-handed subjects had stronger left legs than right (Singh, 1970).

Footedness as a predictor of brain hemispheric dominance causes performance differences in movement and sports performance (Ziyagil, 2011; Eikenberry, McAuliffe, Welsh, Zerpa, McPherson, \& Newhouse, 2008; Arevalo, Lynn, Bagley, Brown, Costa, \& Galpin, 2018). Obviously, it may leads to performance differences in arms of athletes depending on strength differences between right and left legs. On the other side, handedness and footedness related sport performance differences was reported not only in sprint running but also swimming among left and right handers (Ziyagil et al., 2010; Ziyagil, 2011; Gursoy, 2008; Santos, Dos Pereira, Papoti, Bento, Rodacki, \& Dos Santos, 2013; Sevimli, 2016).

In addition, Santos et al. (2013) reported that elite front crawl swimmers are more symmetrical than their sub-elite counterparts. It means that the elite swimmers present more similar propulsive forces between body sides when compared to their sub-elite counterparts (Santos et al., 2013). It was also concluded that hand grip strength symmetry in swimmers can result in better short distance swimming performance due to resultant force effect on technique (Sevimli, 2016).

Strength training and daily usage of legs can cause imbalance between right and left legs and lead to injury during training and competition. To reduce the imbalance between two legs is one of the most important training targets for coaches and physical educators. In a recent case study reported that a strength training program specifically designed to reduce limb difference improved sprinting speed (Brown et al., 2017). Generally, the right and left leg usage are accepted for the determination of leg dominance. Clearly, right and left leg dominance shows the performance of only one leg. For this reason, it was accepted using one of the legs as unilateral footed and using both legs equally as bilateral footed. We hypothesized whether sprint speed changes between unilateral and bilateral foot dominance because the asymmetries in lower limbs may result in decreasing sprinting performance depending on foot preferences.

Generally, the winner athlete in $100 \mathrm{~m}$ race had a the highest acceleration among other competitors because he or she attained his /her top speed in very short time and keep this running speed until the end of the race (Chapman \& Fraser, 2018). As in this study, the $30 \mathrm{~m}$ sprint distance determines positive acceleration of athletes and is basic component of sprint performance. Thus, this study aimed to investigate the sprint speed difference between unilateral and bilateral foot dominance in male and female athletes.

\section{Material and Method}

\section{Participants}

Data were collected from 156 male and 37 females participating in the entrance examination for schools of physical education and sports in Yüzüncü Yll University in the year of 2015. During the exam, the participants were assumed to be highly motivated because they were competing to perform best.

\section{Data Collection}

On the acrylic ground, participants started each sprint from a standing position with one foot on the start line when he or she felt himself or herself ready without external signal or verbal command. Two runs were completed at maximum speed over $30 \mathrm{~m}$ distance. The starting and finishing points were determined by two photocells placed $1 \mathrm{~m}$ above the ground level. The watch was started at first step and stopped when the subject passed the second photocell. The mean running speed was calculated by dividing running distance by running time $(\mathrm{m} / \mathrm{sec})$.

Foot preference was determined by kicking a soccer ball (Nyland, Caborn, Shapiro \& Johnson, 1999). Studies determining leg preference have utilized sport-specific tasks appearing on previous inventories such as kicking a ball.

The participants were asked whether they could kick the ball "with right foot" or "with left foot" or "two foot". The participants with right and left foot dominance were accepted as "unilateral footed" while participants kicking commonly the ball with two foot were recognized as "bilateral footed".

\section{Data Analysis}

All descriptive data was presented as mean, standard deviation, minimum and maximum. The assumption of normality was verified by using Kolmogorov-Smirnov tests $(\mathrm{p}<0.01)$. Mann Whitney $\mathrm{U}$ tests were used for testing differences between two groups.

\section{Results}

Distribution of unilateral and bilateral footed participants in male and females was presented in Table 1 and Graph 1 
while comparison of physical characteristics and mean running speed between unilateral and bilateral footed in males was demonstrated in Table 2. Also, comparison of physical characteristics and mean running speed between unilateral and bilateral footed in females Table 3.

Table 1. Distribution of unilateral and bilateral footed participants in male and females

\begin{tabular}{|c|c|c|c|}
\hline \multirow{2}{*}{$\begin{array}{l}\text { Classification } \\
\text { of foot dominance }\end{array}$} & \multirow[b]{2}{*}{ Groups } & \multicolumn{2}{|c|}{ Genders } \\
\hline & & Males & Females \\
\hline \multirow{3}{*}{$\begin{array}{l}\text { Two Groups } \\
\text { Foot Dominance }\end{array}$} & Unilateral & $127(\% \mathbf{8 1}, \mathbf{4 1})$ & $29(\mathbf{\%} \mathbf{7 8 , 3 8})$ \\
\hline & Bilateral & $29(\% \mathbf{1 8 , 5 9})$ & $8(\% 21,62)$ \\
\hline & Total & $156(\% 100)$ & $37(\% 100)$ \\
\hline Three & Right footed & $102(\% \mathbf{6 5 , 3 8})$ & $28(\% \mathbf{7 8 , 6 8 )}$ \\
\hline Groups & Left footed & $25(\% \mathbf{1 6 , 0 3})$ & $6(\% 16,22)$ \\
\hline \multirow[t]{2}{*}{ Foot Dominance } & Both footed & $29(\% \mathbf{1 8 , 5 9})$ & $3(\% 8,11)$ \\
\hline & Total & $156(\% 100)$ & $37(\% 100)$ \\
\hline
\end{tabular}

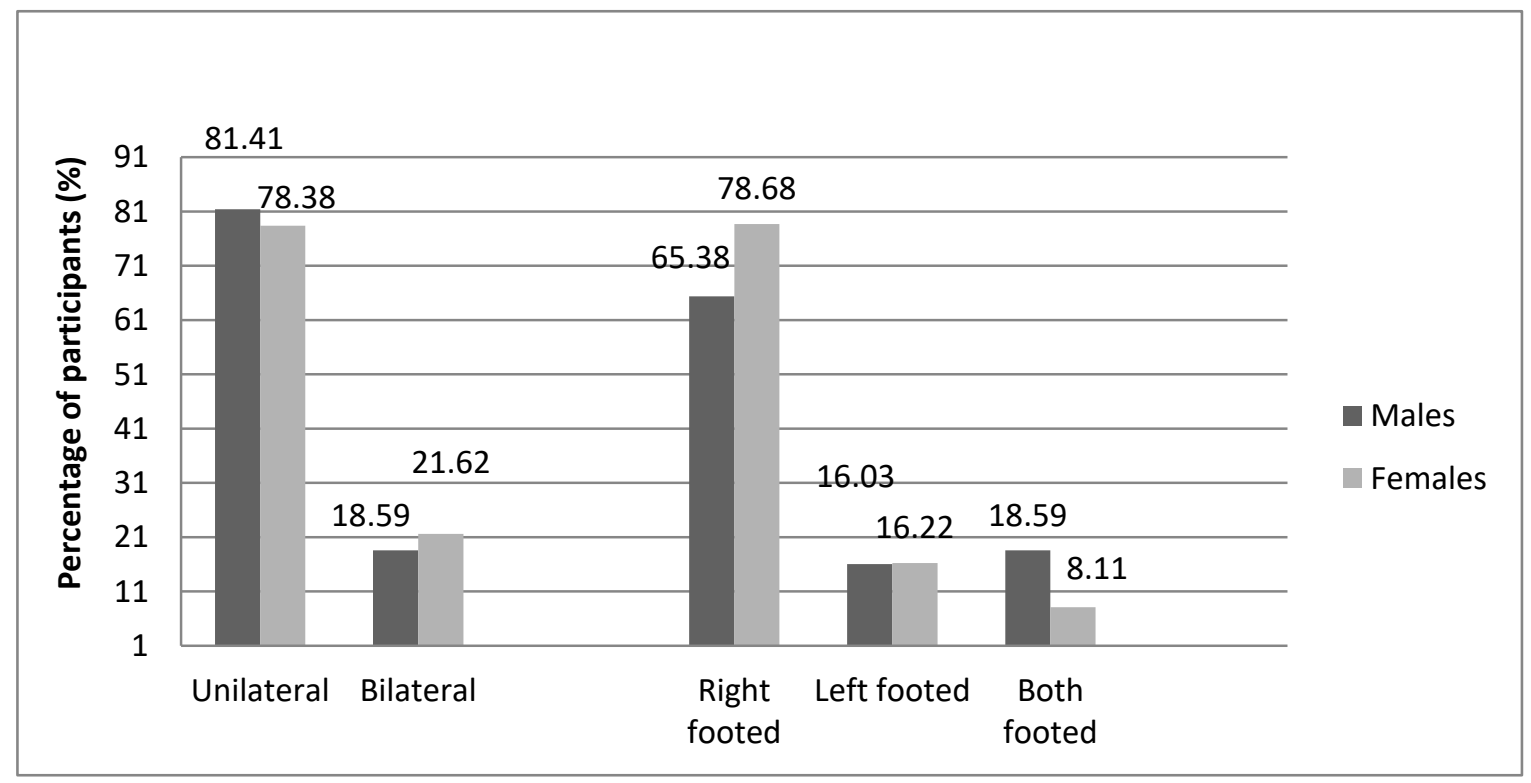

Graph 1. Two and three groups foot dominance classifications in males and females

Table 2. Comparison of physical characteristics and mean running speed between unilateral and bilateral footed in males

\begin{tabular}{|c|c|c|c|c|c|c|c|c|}
\hline Variables & Groups & $\mathrm{n}$ & M & $\mathrm{SD}$ & Min. & Max. & $\begin{array}{c}\text { Mann } \\
\text { Whitney U }\end{array}$ & Asymp \\
\hline \multirow{3}{*}{$\begin{array}{c}\text { Age } \\
\text { (years) }\end{array}$} & Unilateral footed & 127 & 21,10 & 3,28 & 16,00 & 34,00 & \multirow{3}{*}{1729.0} & \multirow{3}{*}{605} \\
\hline & Bilateral footed & 29 & 21,38 & 3,43 & 14,00 & 29,00 & & \\
\hline & Total & 156 & 21,15 & 3,30 & 14,00 & 34,00 & & \\
\hline \multirow{3}{*}{$\begin{array}{l}\text { Body height } \\
(\mathrm{cm})\end{array}$} & Unilateral footed & 127 & 175,42 & 6,62 & 155,00 & 188,00 & \multirow{3}{*}{1505,5} & \multirow{3}{*}{, 125} \\
\hline & Bilateral footed & 29 & 178,10 & 5,73 & 169,00 & 194,00 & & \\
\hline & Total & 156 & 175,92 & 6,54 & 155,00 & 194,00 & & \\
\hline \multirow{3}{*}{$\begin{array}{c}\text { Body weight } \\
(\mathrm{kg})\end{array}$} & Unilateral footed & 127 & 67,28 & 9,17 & 41,00 & 95,00 & \multirow{3}{*}{1550,0} & \multirow{3}{*}{, 184} \\
\hline & Bilateral footed & 29 & 69,62 & 8,00 & 55,00 & 90,00 & & \\
\hline & Total & 156 & 67,71 & 8,99 & 41,00 & 95,00 & & \\
\hline \multirow{3}{*}{ Body Mass İnde( (BMI) } & Unilateral footed & 127 & 21,82 & 2,35 & 15,82 & 29,41 & \multirow{3}{*}{1731,0} & \multirow{3}{*}{,615 } \\
\hline & Bilateral footed & 29 & 21,91 & 1,91 & 18,11 & 26,20 & & \\
\hline & Total & 156 & 21,83 & 2,27 & 15,82 & 29,41 & & \\
\hline \multirow{3}{*}{$\begin{array}{c}\text { First Trial of } \\
\mathbf{3 0} \mathrm{m} \text { Sprint }(\mathrm{m} / \mathrm{sec})\end{array}$} & Unilateral footed & 127 & 6,88 & 0,47 & 3,00 & 7,75 & \multirow{3}{*}{1741,5} & \multirow{3}{*}{,649 } \\
\hline & Bilateral footed & 29 & 6,95 & 0,36 & 6,12 & 7,63 & & \\
\hline & Total & 156 & 6,90 & 0,45 & 3,00 & 7,75 & & \\
\hline \multirow{3}{*}{$\begin{array}{c}\text { Second Trial of } \\
30 \mathrm{~m} \text { Sprint }(\mathrm{m} / \mathrm{sec})\end{array}$} & Unilateral footed & 127 & 6,93 & 0,49 & 3,00 & 8,04 & \multirow{3}{*}{1345,0} & \multirow{3}{*}{, $024 *$} \\
\hline & Bilateral footed & 29 & 7,13 & 0,29 & 6,40 & 7,63 & & \\
\hline & Total & 156 & 6,97 & 0,46 & 3,00 & 8,04 & & \\
\hline
\end{tabular}


* There was a significant difference between two groups at .05 confidence level.

$\mathbf{M}=$ Mean, $\mathbf{S D}=$ Standard deviation of the means.

Table 3. Comparison of physical characteristics and mean running speed between unilateral and bilateral footed in females

\begin{tabular}{|c|c|c|c|c|c|c|c|c|}
\hline Variables & Groups & $\mathbf{n}$ & M. & SD & Min. & Max. & $\begin{array}{c}\text { Mann } \\
\text { Whitney U }\end{array}$ & Asymp \\
\hline \multirow{3}{*}{$\begin{array}{c}\text { Age } \\
\text { Iyears) }\end{array}$} & Unilateral footed & 34 & 19,68 & 2,20 & 16,00 & 25,00 & \multirow{3}{*}{32,5} & \multirow{3}{*}{,298 } \\
\hline & Bilateral footed & 3 & 21,33 & 2,89 & 18,00 & 23,00 & & \\
\hline & Total & 37 & 19,81 & 2,26 & 16,00 & 25,00 & & \\
\hline \multirow{3}{*}{$\begin{array}{l}\text { Body height } \\
\text { (cm) }\end{array}$} & Unilateral footed & 34 & 164,47 & 6,37 & 153,00 & 181,00 & \multirow{3}{*}{45,5} & \multirow{3}{*}{,759 } \\
\hline & Bilateral footed & 3 & 165,00 & 6,25 & 158,00 & 170,00 & & \\
\hline & Total & 37 & 164,51 & 6,28 & 153,00 & 181,00 & & \\
\hline \multirow{3}{*}{$\begin{array}{c}\text { Body weight } \\
\text { (kg) }\end{array}$} & Unilateral footed & 34 & 56,97 & 9,10 & 44,00 & 80,00 & \multirow{3}{*}{43,0} & \multirow{3}{*}{,656 } \\
\hline & Bilateral footed & 3 & 57,00 & 1,00 & 56,00 & 58,00 & & \\
\hline & Total & 37 & 56,97 & 8,72 & 44,00 & 80,00 & & \\
\hline \multirow{3}{*}{$\begin{array}{c}\text { Body Mass Index } \\
\text { (BMI) }\end{array}$} & Unilateral footed & 34 & 21,06 & 3,23 & 16,60 & 31,25 & \multirow{3}{*}{45,500} & \multirow{3}{*}{, 760} \\
\hline & Bilateral footed & 3 & 21,01 & 1,93 & 19,72 & 23,23 & & \\
\hline & Total & 37 & 21,06 & 3,13 & 16,60 & 31,25 & & \\
\hline \multirow{3}{*}{$\begin{array}{l}\text { First Trial of } \\
30 \mathrm{~m} \text { Sprint }(\mathrm{m} / \mathrm{sec})\end{array}$} & Unilateral footed & 34 & 5,59 & 0,69 & 2,81 & 6,88 & \multirow{3}{*}{17,000} & \multirow{3}{*}{, 058} \\
\hline & Bilateral footed & 3 & 6,35 & 0,63 & 5,66 & 6,88 & & \\
\hline & Total & 37 & 5,65 & 0,71 & 2,81 & 6,88 & & \\
\hline \multirow{3}{*}{$\begin{array}{l}\text { Second Trial of } \\
30 \mathrm{~m} \text { Sprint }(\mathrm{m} / \mathrm{sec})\end{array}$} & Unilateral footed & 34 & 5,67 & 0,70 & 2,81 & 6,79 & \multirow{3}{*}{18,500} & \multirow{3}{*}{070} \\
\hline & Bilateral footed & 3 & 6,33 & 0,46 & 5,88 & 6,79 & & \\
\hline & Total & 37 & 5,72 & 0,70 & 2,81 & 6,79 & & \\
\hline
\end{tabular}

* There was a significant difference between two groups at .05 confidence level.

$\mathbf{M}=$ Mean, $\mathbf{S D}=$ Standard deviation of the means.

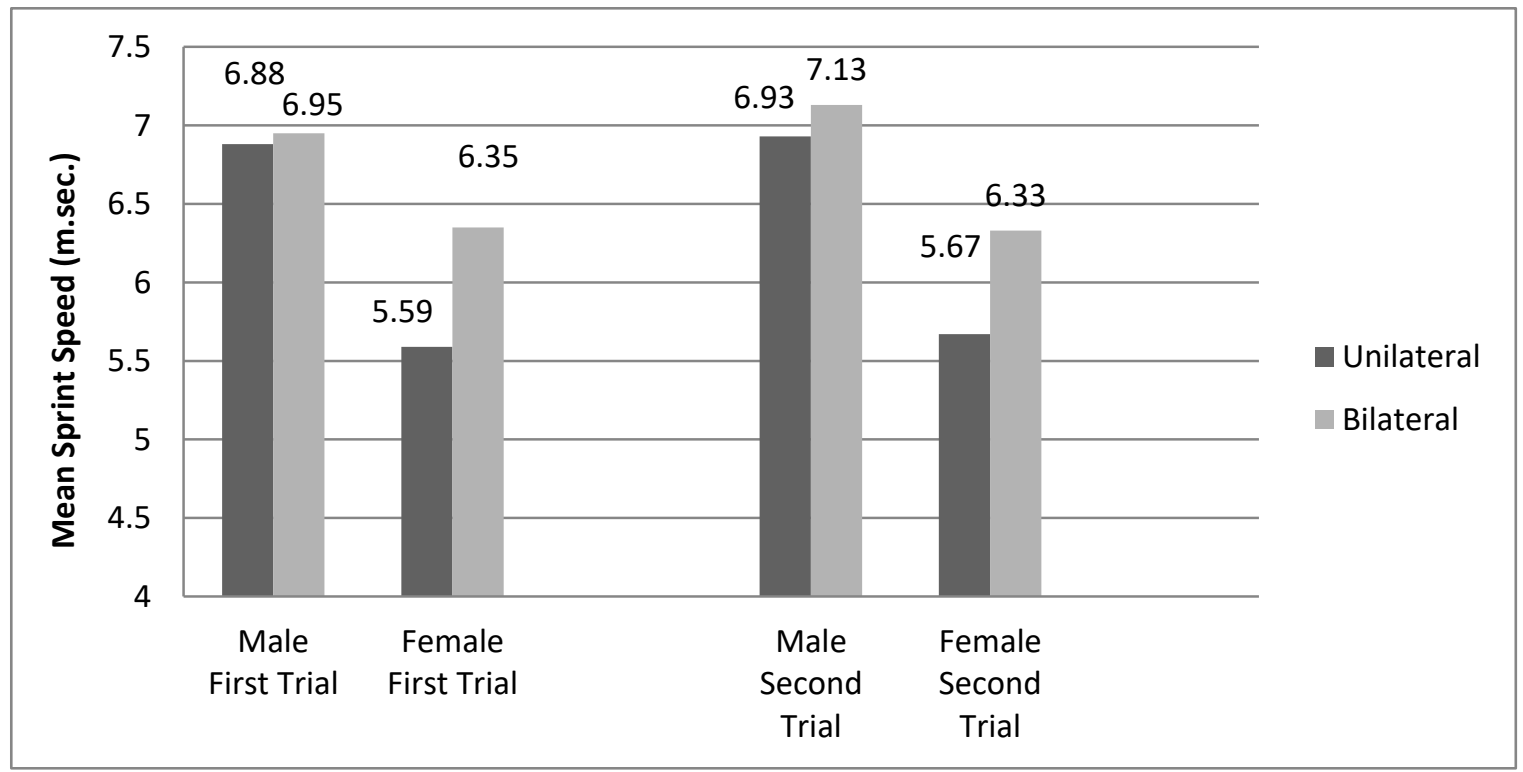

Graph 2. Comparison of mean sprint spped between unilateral and bilateral footed athletes in males and females during first and second trials of $30 \mathrm{~m}$ sprint run

\section{Discussion}

Footedness as a predictor of brain hemispheric dominance can cause performance differences in sprinting and sports performance. The asymmetries in upper and lower limbs may result in decreasing speed during sprint running performance by the differences in strength, flexibility and posture depending on hand preferences (Chapman \& Fraser, 2018). Thus, this study aimed to investigate the sprint speed difference between unilateral and bilateral foot dominance in male and female athletes.

Acceleration during sprinting requires maximal force from the extensor muscles of the hip, knee, and ankle in the right 
and left legs. In addition, acceleration of the arms enhances acceleration by increasing the ground reaction force. Maximal running speed cannot be sustained for much longer than $4 \mathrm{~s}$ due to limited the rate of chemical energy supply. Success in running depends largely on muscular capabilities, although body shape and proportion cannot be ignored (Chapman \& Fraser, 2018).

The results of this study showed that no significant difference was observed between unilateral and bilateral footers in the view of physical characteristics in male and females. There was only significant difference in the second attempt of 30 meters sprints between physically similar two groups in males. In the first $30 \mathrm{~m}$ sprint, males' mean sprint speed was 6.88 $\mathrm{m} / \mathrm{sec}$ for unilateral footed and $6.95 \mathrm{~m} / \mathrm{sec}$ for bilateral footed participants. Bilateral footed males were $1.02 \%$ faster than unilateral footers. However, this difference was statistically insignificant. In the second $30 \mathrm{~m}$ sprint, males' mean sprint speed was $6.93 \mathrm{~m} / \mathrm{sec}$ for unilateral footed and $7.93 \mathrm{~m} / \mathrm{sec}$ for bilateral footed participants. Bilateral footed males were $2.81 \%$ faster than unilateral footers. Clearly this difference was statistically significant at 0.05 levels (Graph 2).

On the other hand, mean sprint speed was $5.59 \mathrm{~m} / \mathrm{sec}$ for unilateral footed and $6.35 \mathrm{~m} / \mathrm{sec}$ for bilateral footed female participants in the first $30 \mathrm{~m}$ sprint. Bilateral footed females were $11.97 \%$ faster than unilateral footers. However, this difference was statistically insignificant. In the second $30 \mathrm{~m}$ sprint, females' mean sprint speed was $5.67 \mathrm{~m} / \mathrm{sec}$ for unilateral footed and $6.33 \mathrm{~m} / \mathrm{sec}$ for bilateral footed participants. Bilateral footed females were $10.43 \%$ faster than unilateral footers. However, this difference was not statistically significant (Graph 2).

In contrast to males, there was a greater sprint speed difference between unilateral and bilateral foot dominance participants in females. These insignificant differences in the sprinting speed of females may be partly due to lower number of bilateral athletes in our study. The superiority of the bilateral footed athletes is due to the symmetrical power production of right and left legs in the linear direction during sprinting.

A number of studies have shown that similar contributions to propulsion might be anticipated from both legs. However, there may be differences in technique coordination and propulsive forces between left and right legs during sprinting. Large strength imbalances on foot dominance were observed in both sedentary and exercise-trained individuals (Ziyagil et al., 2010; McGrath et al., 2016; Brown et al., 2017). These asymmetries can hinder sprinting speed or physical performance level leading to low mechanical efficiency (McGrath et al., 2016; Ziyagil, 2011; Singh, 1970) and may be a risk for injury risk (McGrath et al., 2016; Brown et al., 2017). Similarly, Bassey and Harries (1991) hypothesized that handedness and strength asymmetry in both arms and legs may result in lower swimming performance in adolescent males (Bassey \& Harries, 1991). Coaches need the information about swimmers for talent identification and monitoring trainings. They should know the importance of hand grip strength symmetry in swimmers can result in better short distance swimming performance.

It can be concluded that bilateral footed athletes seem to have some innate neurologic superiority or mechanical advantage for acceleration in sprinting compared to unilateral footed athletes including right and left footers in males. Although similar trend was observed in females, differences in mean sprinting speed were not statistically significant due to small number of bilateral footed athletes in females. Finally, it may be considered that neither left brain hemisphere nor left brain hemisphere dominance is related to sprinting ability but bilateral foot dominance may contribute to better acceleration during $30 \mathrm{~m}$ sprint, creating equal propulsive force from right and left sides for fast linear displacement.

In conclusion, unilateral and bilateral foot dominance can be useful criteria in the selection of talented sprinters and in the planning and monitoring of sprint training.

Further research is required to assess the development of lateral asymmetries with large sample of athletes in order to investigate the influence of footedness on running speed in sprinting performance.

\section{References}

Arevalo, J. A., Lynn, S. K., Bagley, J. R., Brown, L. E., Costa, P. B., \& Galpın, A. J. (2018). Lower-Limb Dominance, Performance, and Fiber Type in Resistance-trained Men. Med. Sci. Sports Exerc., 50(5), 1054-1060. https://doi.org/10.1249/MSS.0000000000001533

Bassey, E. J., \& Harries, U. J. (1991). Normal values for handgrip strength in 920 men and women aged over 65 years, and longitudinal changes over 4 years in 620 survivors. Clinical Science, 84, 331-337. https://doi.org/10.1042/cs0840331

Brown, S. R., Feldman, E. R., Cross, M. R., et al. (2017). The potential for a targeted strength training programme to decrease asymmetry and increase performance: a proof-of-concept in sprinting. Int J Sports Physiol Perform. 12(10), 1392-1395. https://doi.org/10.1123/ijspp.2016-0590

Chapman, A. E., \& Fraser, S. (2018). Biomechanical analysis of fundamental human movements. Human Kinetic 
Publication, 117-118.

Chapman, J. P., Chapman, L. J., \& Allen, J. J. (1987). The measurement of foot preference. Neuropsychologia, 25, 579-584. https://doi.org/10.1016/0028-3932(87)90082-0

Eikenberry, A., McAuliffe, J., Welsh, T. N., Zerpa, C., McPherson, M., \& Newhouse, I. (2008). Starting with the "right" foot minimizes sprint start time. Acta Psychologica, 127, 495-500. https://doi.org/10.1016/j.actpsy.2007.09.002

Gabbard, C. (1993). Foot laterality during childhood: a review. International Journal of Neuroscience, 72, $175-182$. https://doi.org/10.3109/00207459309024106

Gursoy, R. (2008). Effects of left or right hand preference on the success of boxers in Turkey. British Journal of Sports Medicine, 43(2), 142-144. https://doi.org/10.1136/bjsm.2007.043547

McGrath, T. M., Waddington, G., \& Scarvell, J. M., et al. (2016). The effect of limb dominance on lower limb functional performance—a systematic review. J Sports Sci. 34(4), 289-302. https://doi.org/10.1080/02640414.2015.1050601

Nyland, J. A., Caborn, D., Shapiro, R., \& Johnson, D. L. (1999). Crossover cutting during hamstring fatigue produces transverse plane knee control deficits. Journal of Athletic Training, 34(2), 137-143.

Peters, M. (1990). Neuropsychological identification of motor problems: can we learn something from the feet and legs that hands and arms will not tell us? Neuropsychological Review, 1, 165-183.

Santos, K., Dos Pereira G., Papoti, M., Bento, P. C. B., Rodacki, A., \& Dos Santos, K. B. (2013). Propulsive Force Asymmetry during Tethered-Swimming. International Journal of Sports Medicine, 34(7), 60611. https://doi.org/10.1055/s-0032-1327575

Searleman, A. (1980). Subject variables and cerebral organization. Cortex, 16, $239-254$. https://doi.org/10.1016/S0010-9452(80)80060-8

Sevimli, D. (2016). Correlations among handedness, handgrip strength and front crawl swimming performance in adolescents. Kinesiologia Slovenica, 22(3), 23-30.

Singh, I. (1970). Functional asymmetry in the lower limbs. Acta Anatomica, 77, 131-138. https://doi.org/10.1159/000143535

Ziyagil, M. A. (2011). Handedness and footedness: relations to differences in sprinting speed and multiple sprints performance in prepubertal boys. Percept Motor Skill, 112, 440-450. https://doi.org/10.2466/10.19.25.PMS.112.2.440-450

Ziyagil, M. A., Gursoy, R., Dane, S., \& Yuksel, R. (2010). Left-handed wrestlers are more successful. Perceptual and Motor Skills, 111, 65-70. https://doi.org/10.2466/04.05.19.25.PMS.111.4.65-70

\section{Copyrights}

Copyright for this article is retained by the author(s), with first publication rights granted to the journal.

This is an open-access article distributed under the terms and conditions of the Creative Commons Attribution license which permits unrestricted use, distribution, and reproduction in any medium, provided the original work is properly cited. 